\title{
Vitreous flow rates through dual pneumatic cutters: effects of duty cycle and cut rate
}

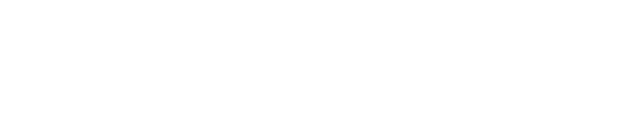

\section{Dina Joy K Abulon}

Medical Affairs, Alcon Research, Ltd, Lake Forest, CA, USA
Correspondence: Dina Joy K Abulon Alcon Research, Ltd, 205II Lake Forest Drive, Lake Forest, CA 92630, USA

$\mathrm{Tel}+$ I 9495057586

Fax + I 9497536270

Email dina.abulon@alcon.com
Purpose: We aimed to investigate effects of instrument settings on porcine vitreous flow rates through dual pneumatic high-speed vitrectomy probes.

Methods: The CONSTELLATION ${ }^{\circledR}$ Vision System was tested with 250, 450, and $650 \mathrm{mmHg}$ of vacuum using six ULTRAVIT $^{\circledR}$ vitrectomy probes of each diameter $\left(25+{ }^{\circledR}, 25,23\right.$, and 20 gauge) operated from 500 cuts per minute (cpm) up to 5,000 cpm. Duty cycle modes tested included biased open, 50/50, and biased closed. Flow rates were calculated by assessing the change in weight of porcine eyes during vitreous aspiration. Volumetric flow rate was measured with a computer-connected electronic scale.

Results: At lower cut rates, the biased open mode produced higher flow than did the 50/50 mode, which produced higher flow than did the biased closed mode. In the biased closed and $50 / 50$ modes, vitreous flow rates tended to increase with increasing cut rate. Vitreous flow rates in the biased open duty cycle mode remained relatively constant across cut rates.

Conclusion: Vitreous flow rates through dual pneumatic vitrectomy probes could be manipulated by changing the duty cycle modes on the vitrectomy system. Differences in duty cycle behavior suggest that high-speed cut rates of 5,000 cpm may optimize vitreous aspiration.

Keywords: enhanced 25-gauge vitrectomy, 25-gauge vitrectomy, 20-gauge vitrectomy, 23-gauge vitrectomy, aspiration, Constellation Vision System

\section{Introduction}

Flow rate of pure fluid through a vitrectomy probe that is operating without cutting action can be described by Poiseuille's law, shown in the following equation, in which $\Delta \mathrm{P}$ represents the difference in pressure across the length of the probe needle (related to applied vacuum settings), $\mathrm{L}$ is the length of the probe needle, $\mathrm{r}$ is the internal radius of the probe, and $\eta$ is the viscosity of the aspirated liquid. ${ }^{1}$

$$
\text { Flow }=\frac{\Delta P \cdot \pi \cdot r^{4}}{\eta \cdot L \cdot 8}
$$

In contrast, flow behavior of vitreous humor during vitrectomy is difficult to characterize because of the variability in the composition of the aspirated material throughout the procedure. ${ }^{2}$ Under certain conditions (eg, aging), the interaction of collagen and hyaluronic acid becomes disrupted, resulting in liquefaction of the vitreous; ${ }^{3}$ similar mechanisms may occur during vitrectomy as buffered saline solution (BSS) is infused in the eye to maintain intraocular pressure. In addition, an inconsistent combination of vitreous and BSS is aspirated during the procedure; thus, the ratio of vitreous to BSS (and therefore the overall viscosity of the aspirated material) varies throughout the surgery. 
Flow rate may also be affected by vitrectomy system mechanics (eg, duty cycle modulation), probe design (eg, inner diameter and port geometry), and performance. When aspirating pure BSS with spring-return probes, high-speed cut rates tend to reduce flow rates because of alterations in duty cycle (ie, the percentage of time the cutter port is open relative to one complete cutting cycle). Spring-return pneumatic cutters rely on air to drive the cutter into a closed position and a spring to force the cutter back to its original open position. ${ }^{4}$ Thus, an increase in cut speed in springreturn probes also decreases the ratio of port open time to cut cycle time (ie, a reduction in duty cycle) and reduces flow rate. Because of this design, these spring pneumatic devices have limited control over duty cycle. Newer dual pneumatic cutters use separate air lines to control opening and closing of the cutter, resulting in several duty cycles: biased open (maximum time the port is open), 50/50 (port opened $50 \%$ of the time), and biased closed (minimum time the port is open). In aqueous solutions, the biased open duty cycle displays similar fluid behavior as that observed with spring-return pneumatic devices, whereas the biased closed duty cycle increases flow rate with increasing cutting speed; the 50/50 duty cycle allows a similar flow rate at all cut rates. However, in viscous material, such as vitreous, fluid dynamics change because the viscosity of the material increases resistance of flow through the probe. ${ }^{5}$ High cut rates result in smaller vitreous pieces that are more easily aspirated through the probe; thus, the relationship between cut rate, duty cycle, and flow rate becomes more dynamic. ${ }^{6}$

Previous studies have evaluated flow rates through various vitrectomy probes using pure BSS, ${ }^{5,7,8}$ vitreous, ${ }^{5,7,8}$ or material with a much greater viscosity than BSS (eg, egg white). ${ }^{1}$ This study expanded on these works through investigation of porcine vitreous flow rates through probes of various diameters (enhanced 25, 25, 23, and 20 gauge) operated in the three different duty cycle modes, with different applied cut rates and vacuums. The results may help physicians understand flow dynamics during vitrectomy and better inform their choice of probes and instrument settings for safe and efficient vitreoretinal surgeries.

\section{Materials and methods}

A CONSTELLATION ${ }^{\circledR}$ Vision System (Alcon Laboratories, Inc., Fort Worth, TX, USA) was tested with vacuum settings of 250,450, and $650 \mathrm{mmHg}$ using six ULTRAVIT ${ }^{\circledR}$ vitrectomy probes (Alcon Laboratories, Inc) of each available diameter $\left(25+{ }^{\circledR}\right.$ [enhanced 25], 25, 23, and 20 gauge). Compared with the 25 -gauge probe, the enhanced 25-gauge probe has more stiffness, a larger inner diameter, and a larger port opening. ${ }^{9}$ The probes were tested at each of the three duty cycle settings of the vitrectomy system and were labeled as biased open, $50 / 50$ (50\% port open), and biased closed. Cut rates ranged from 500 to 5,000 cuts per minute (cpm).

Porcine eyes were obtained from Sierra for Medical Science (Whittier, CA, USA) and were tested within 12 hours of slaughter. Each eye was refrigerated until immediately before testing. One porcine eye was used per test. Before flow rate testing, vitreous density was evaluated by extracting vitreous from an eye and measuring its mass and volume in a tared graduated cylinder, with 3 to $4 \mathrm{~mL}$ vitreous. Density measurements were repeated for 10 eyes and then averaged.

A Styrofoam ${ }^{\mathrm{TM}}$ cube with $7.6 \mathrm{~cm}$ edges was prepared as an eye holder by hollowing out a $2.5 \mathrm{~cm}$ diameter halfsphere. A porcine eye was secured in the spherical recess with T-pins. Using a scalpel, an incision was made through the pars plana, 3 to $4 \mathrm{~mm}$ posterior to the limbus. The incision was continued in an annulus through the ciliary body in the region of the pars plana. The anterior chamber of the eye was removed, along with any associated vitreous attachments from the posterior side of the anterior chamber. The Styrofoam block, with the porcine eye secured into it, was placed on an electronic balance (model EK-600i; A\&D Engineering, Inc., San Jose, CA, USA). Using a clamp and a lab stand, the vitrectomy probe to be tested was secured vertically over the balance and was inserted into the center of the vitreous bolus.

The electronic balance was connected to a data acquisition board (National Instruments Corp, Austin, TX, USA) in a personal computer. A program was written for LabVIEW (National Instruments Corp) to measure mass with time. Mass was measured in 1-second bins for a duration that depended on the flow rate. The 20 -gauge probes were tested for approximately 10 to 15 seconds, 23 -gauge probes were tested for 30 to 45 seconds, and 25-gauge probes for 60 seconds. The LabVIEW program divided the measured mass flow by the previously calculated average porcine vitreous density (a required user input), yielding the volume flow, with time as an output file that the computer interpreted as a Microsoft ${ }^{\circledR}$ Excel $^{\circledR}$ file (Microsoft Corp, Redmond, WA, USA). Before each test, the balance was zeroed, and the appropriate vitrectomy system settings were chosen. The LabVIEW program was activated, and the vitreous cutter was engaged. Once the flow rate stabilized (after $\sim 3$ seconds, depending on experimental parameters), the vitreous flow rate was recorded. 
Vitreous flow rates were compared with previously presented flow rates of BSS..$^{10}$ In measuring aqueous flow, key differences from the BSS measurement system included use of a closed-globe nondeformable model eye, applied infusion pressure of $30 \mathrm{mmHg}$, and a flow meter instead of an electric balance.

For each test, the vitreous flow rate was calculated as the average of data points after the initial time to stabilize and before any inadvertent aspiration of air when all vitreous was removed from the globe. Flow rates were compared using Student's $t$-test with statistical significance set to $P<0.05$. Trends were examined by linear regression in Microsoft Excel. A series was considered to be linearly increasing if it had a positive slope and $R^{2} \geq 0.81$ (the critical value for four degrees of freedom with $\alpha=0.05$ ). All data are presented as mean \pm standard deviation (SD) unless otherwise noted.

A

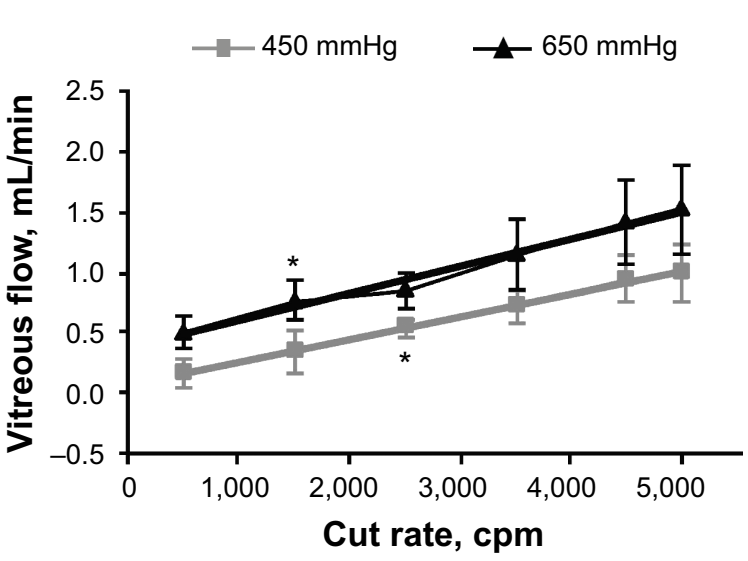

\section{Results}

\section{Enhanced 25-gauge results}

With $250 \mathrm{mmHg}$ vacuum, vitreous flow through the enhanced 25 -gauge probe yielded values within experimental error of zero, so data were evaluated only with 450 and $650 \mathrm{mmHg}$ of vacuum. Results showed that overall flow rates for enhanced 25 -gauge probes (Figure 1) were $1.6 \pm 0.6$ times higher than for 25 -gauge probes (Figure 2).

In the biased closed duty cycle mode, vitreous flow was strongly dependent on cut rate, ranging from $0.5 \pm 0.2 \mathrm{~mL} / \mathrm{min}$ (at $500 \mathrm{cpm}$ ) to $1.5 \pm 0.5 \mathrm{~mL} / \mathrm{min}$ (at $5,000 \mathrm{cpm}$ ) at $650 \mathrm{mmHg}$ vacuum (Figure 1A). The slopes of the trend lines for these data were $0.2 \mu \mathrm{L} /$ cut with the 450 and $650 \mathrm{mmHg}$ vacuum settings (both $R^{2}>0.9$ ). Average flow rate with enhanced 25 -gauge probes in the biased closed duty cycle mode was $1.6 \pm 0.7$ times higher than the corresponding flow rates with 25 -gauge probes.

B $50 / 50$

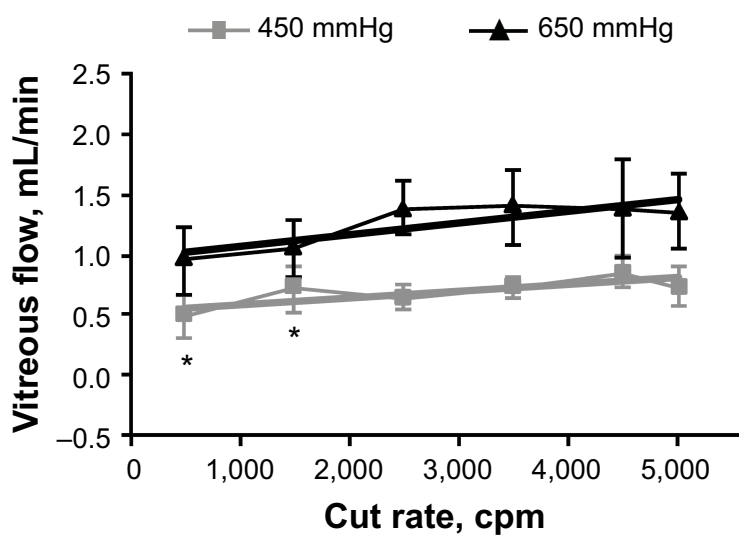

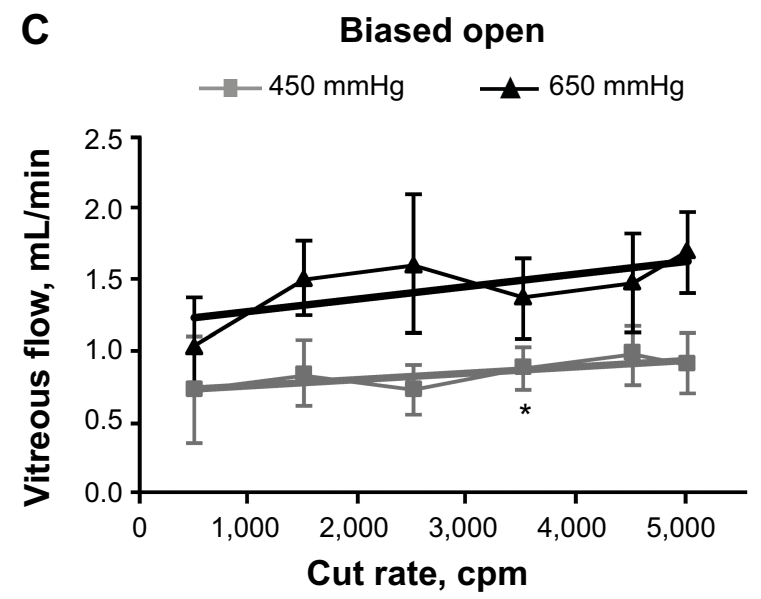

Figure I Vitreous flow through enhanced 25-gauge probes.

Notes: Each data point represents the average flow rate calculated from six probes, with error bars representing $95 \%$ Cls. The asterisks mark flow rate values that are significantly higher than the corresponding values obtained with 25 -gauge probes $(P<0.05)$. (A) Biased closed duty cycle; (B) $50 / 50$ duty cycle; (C) biased open duty cycle. Bold lines indicate linear regression trends.

Abbreviations: $\mathrm{Cl}$, confidence interval; cpm, cuts per minute. 

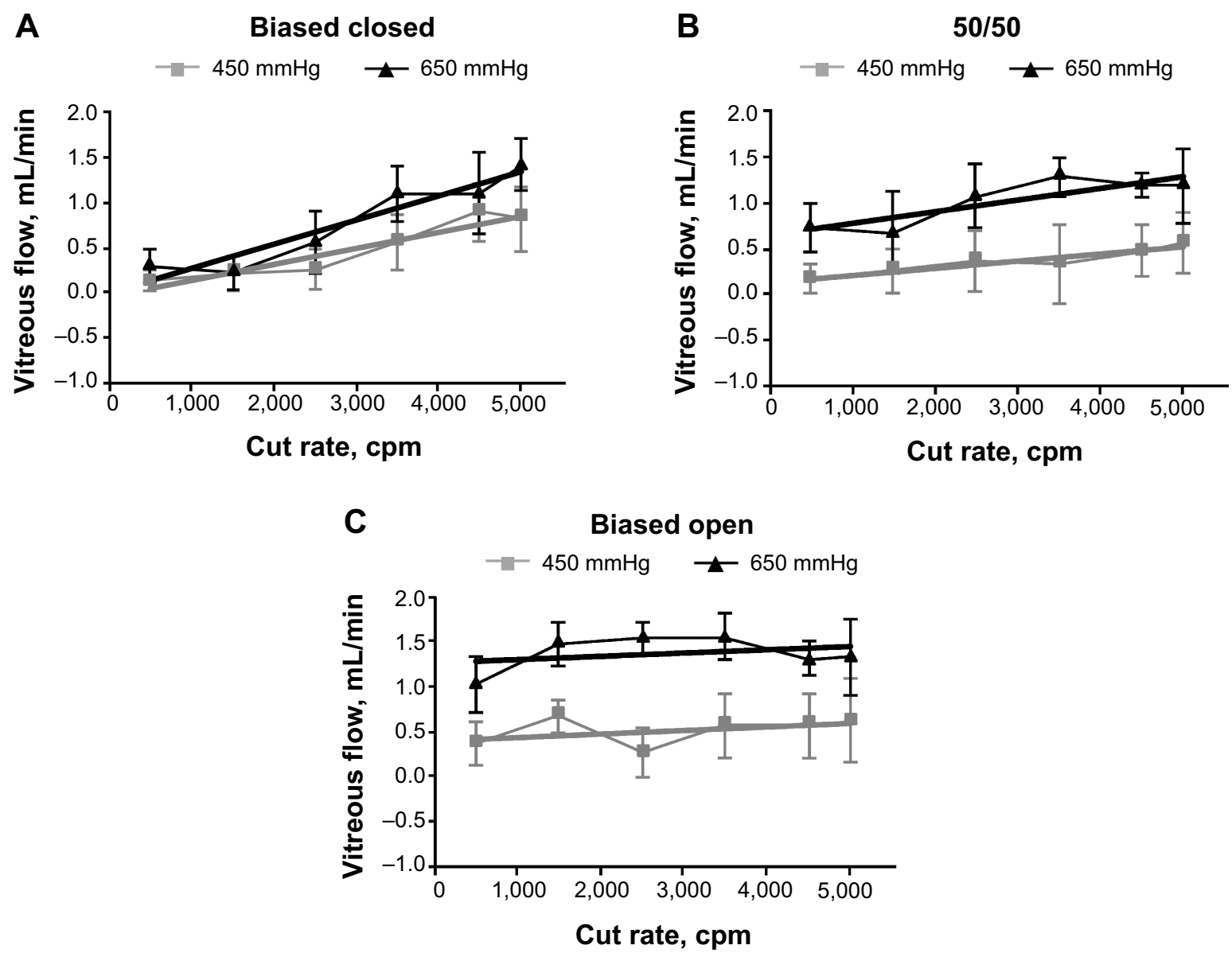

Figure 2 Vitreous flow through 25-gauge probes.

Notes: Each data point represents the average flow rate calculated from six probes, with error bars representing $95 \%$ Cls. (A) Biased closed duty cycle; (B) 50/50 duty cycle; (C) biased open duty cycle. Bold lines indicate linear regression trends.

Abbreviations: $\mathrm{Cl}$, confidence interval; cpm, cuts per minute.

Compared with the biased closed duty cycle mode, vitreous flow in the 50/50 duty cycle mode was not as strongly dependent on cut rate. With both vacuums, flow with 50/50 duty cycle increased nonlinearly with cut rate (slope $=0.1 \mu \mathrm{L} /$ cut at $650 \mathrm{mmHg}$ and $0.06 \mu \mathrm{L} /$ cut at $450 \mathrm{mmHg}$ [both $\left.R^{2} \leq 0.7\right]$ ). At $650 \mathrm{mmHg}$, flow rate ranged from $0.9 \pm 0.3 \mathrm{~mL} / \mathrm{min}$ (at $500 \mathrm{cpm}$ ) to $1.4 \pm 0.4 \mathrm{~mL} / \mathrm{min}$ (at $3,500 \mathrm{cpm}$ ). In the $50 / 50$ duty cycle mode with cut rate at $500 \mathrm{cpm}$, the vitreous flow was significantly higher $(P<0.05)$ than the corresponding flow in the biased closed duty cycle mode for both vacuum series (450 and $650 \mathrm{mmHg}$ ) (Figure 1B). At 5,000 cpm, flow rates with the $50 / 50$ duty cycle mode were statistically similar to corresponding flow rates in the biased closed duty cycle mode. Average flow rate with enhanced 25-gauge probes in the $50 / 50$ duty cycle mode was $1.7 \pm 0.6$ times higher than the corresponding flow rates with 25 -gauge probes.

In the biased open duty cycle mode, vitreous flow was essentially constant across cut rates (Figure 1C). At $650 \mathrm{mmHg}$ vacuum, minimum flow was $1.0 \pm 0.4 \mathrm{~mL} / \mathrm{min}$ (at $500 \mathrm{cpm}$ ), and maximum flow was $1.6 \pm 0.4 \mathrm{~mL} / \mathrm{min}$ (at $5,000 \mathrm{cpm}$ ). Trend lines for the data with the 450 and $650 \mathrm{mmHg}$ vacuum settings had low correlation coefficients (both $R^{2}<0.66$ ). Average flow rate with enhanced 25 -gauge probes in the biased open duty cycle mode was $1.6 \pm 0.6$ times higher than the corresponding flow rates with 25 -gauge probes. Vitreous flow at $500 \mathrm{cpm}$ was not significantly different from vitreous flow at 5,000 cpm, with $450 \mathrm{mmHg}$. In the biased open duty cycle mode with cut rate at $500 \mathrm{cpm}$, the vitreous flow was significantly higher $(P<0.05)$ than the corresponding flow in the biased closed duty cycle mode for the 450 and $650 \mathrm{mmHg}$ vacuum series.

\section{5 -gauge results}

With $250 \mathrm{mmHg}$ of vacuum, vitreous flow through the 25 -gauge probe was too low to be recorded by the electronic balance, so data were evaluated only with 450 and $650 \mathrm{mmHg}$ vacuum (Figure 2). 
In the biased closed duty cycle mode with $650 \mathrm{mmHg}$ vacuum, vitreous flow was strongly dependent on cut rate, ranging from $0.2 \pm 0.2 \mathrm{~mL} / \mathrm{min}$ (at $1,500 \mathrm{cpm}$ ) to $1.4 \pm 0.4 \mathrm{~mL} / \mathrm{min}$ (at $5,000 \mathrm{cpm}$ ) (Figure 2A). The slopes of trend lines for these data were $0.2 \mu \mathrm{L} /$ cut with the $450 \mathrm{mmHg}$ vacuum setting and $0.3 \mu \mathrm{L} /$ cut with the $650 \mathrm{mmHg}$ vacuum setting (both $R^{2}=0.9$ ).

Slopes of the trend lines for the 50/50 duty cycle mode data were $0.08 \mu \mathrm{L} /$ cut with the $450 \mathrm{mmHg}$ vacuum setting $\left(R^{2}=0.9\right)$ and $0.1 \mu \mathrm{L} /$ cut with the $650 \mathrm{mmHg}$ vacuum setting $\left(R^{2}=0.7\right)$. With $650 \mathrm{mmHg}$ of vacuum, flow rate ranged from a minimum of $0.7 \pm 0.6 \mathrm{~mL} / \mathrm{min}$ (at $1,500 \mathrm{cpm}$ ) to a maximum of $1.3 \pm 0.3 \mathrm{~mL} / \mathrm{min}$ (at 3,500 cpm). At 5,000 cpm, maximum flow rates with the 50/50 duty cycle mode were statistically similar to the corresponding maximum flow rates in the biased closed duty cycle mode. Compared with the biased closed duty cycle mode, vitreous flow in the 50/50 duty cycle mode (Figure 2B) was not as strongly dependent on cut rate.

In the biased open duty cycle mode, vitreous flow was essentially constant across cut rates (Figure 2C). With $650 \mathrm{mmHg}$ of vacuum, minimum flow was $1.0 \pm 0.4 \mathrm{~mL} / \mathrm{min}$ (at $500 \mathrm{cpm}$ ) and maximum flow was $1.5 \pm 0.2 \mathrm{~mL} / \mathrm{min}$ (at 2,500 cpm). Trend lines for these data had low correlation coefficients (both $R^{2} \leq 0.2$ ). Vitreous flow at $500 \mathrm{cpm}$ was not significantly different from vitreous flow at $5,000 \mathrm{cpm}$ under either vacuum condition.

\section{3 -gauge results}

Flow rates through 23-gauge probes are shown in Figure 3. Maximum flow rates with each duty cycle setting (at 5,000 cpm and $650 \mathrm{mmHg}$ ) with 23 -gauge probes were

B $650 \mathrm{mmHg}$

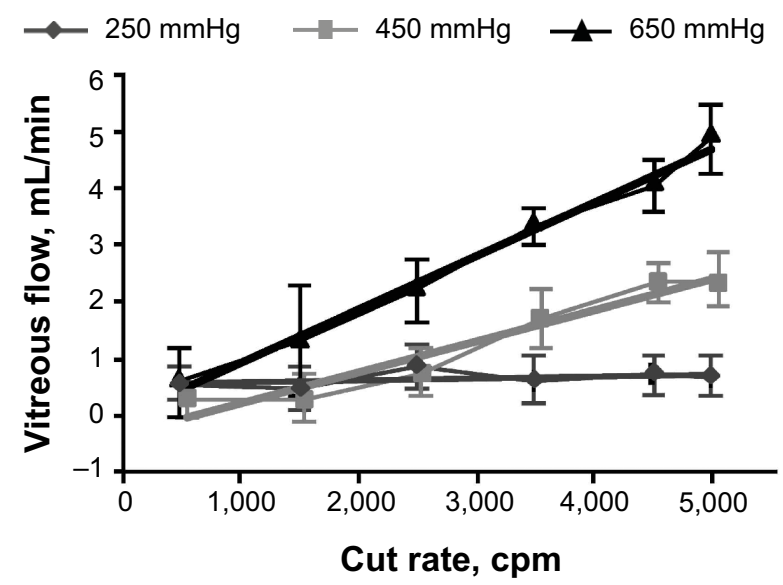

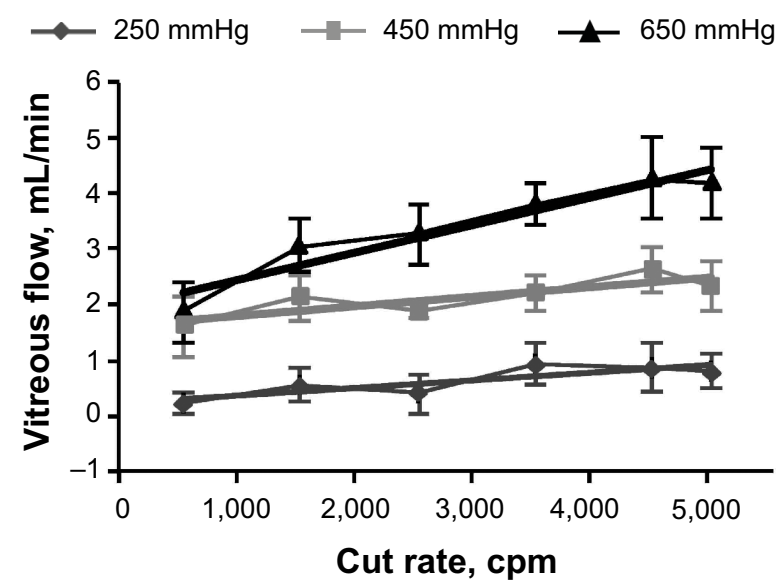

C Biased open

$\neg 250 \mathrm{mmHg} \longrightarrow 450 \mathrm{mmHg} \quad \longrightarrow 650 \mathrm{mmHg}$

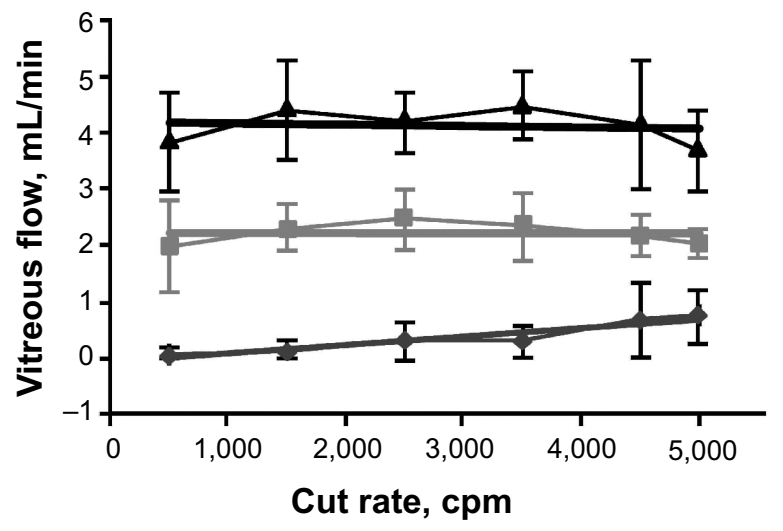

Figure 3 Vitreous flow through 23-gauge probes.

Notes: Each data point represents the average flow rate calculated from six probes, with error bars representing $95 \%$ Cls. (A) Biased closed duty cycle; (B) $50 / 50$ duty cycle; (C) biased open duty cycle. Bold lines indicate linear regression trends.

Abbreviations: $\mathrm{Cl}$, confidence interval; cpm, cuts per minute. 
$3.3 \pm 0.4$ times higher than the corresponding maximum flow rates with 25 -gauge probes.

In the biased closed duty cycle mode at $650 \mathrm{mmHg}$ vacuum, vitreous flow was strongly dependent on cut rate, ranging from $0.6 \pm 0.8 \mathrm{~mL} / \mathrm{min}$ (at $500 \mathrm{cpm}$ ) to $4.8 \pm 0.8 \mathrm{~mL} / \mathrm{min}$ (at 5,000 cpm) (Figure 3A). The slopes of trend lines calculated for these data were $0.2 \mu \mathrm{L} /$ cut with the $250 \mathrm{mmHg}$ vacuum setting, $0.5 \mu \mathrm{L} /$ cut with the $450 \mathrm{mmHg}$ vacuum setting, and $0.9 \mu \mathrm{L} /$ cut with the $650 \mathrm{mmHg}$ vacuum setting (all $R^{2} \geq 0.9$ ).

Compared with the biased closed duty cycle mode, vitreous flow in the 50/50 duty cycle mode was not as strongly dependent on cut rate (Figure 3B). Slopes of the trend lines calculated for these data were $0.1 \mu \mathrm{L} /$ cut with the $250 \mathrm{mmHg}$ vacuum setting $\left(R^{2}=0.7\right), 0.2 \mu \mathrm{L} /$ cut with the $450 \mathrm{mmHg}$ vacuum setting $\left(R^{2}=0.7\right)$, and $0.5 \mu \mathrm{L} /$ cut with the $650 \mathrm{mmHg}$ vacuum setting $\left(R^{2}=0.9\right)$. In the $50 / 50$ duty cycle mode at $500 \mathrm{cpm}$, the vitreous flow was significantly higher $(P<0.05)$ than the corresponding flow in the biased closed duty cycle mode for the 450 and $650 \mathrm{mmHg}$ settings. At 5,000 cpm, maximum flow with the 50/50 duty cycle setting was $4.1 \pm 0.8 \mathrm{~mL} / \mathrm{min}$ (with $650 \mathrm{mmHg}$ vacuum), statistically similar to the corresponding maximum flow rate in the biased closed duty cycle setting.

In the biased open duty cycle mode, vitreous flow was essentially constant across cut rates (Figure 3C), with all $R^{2} \leq 0.2$. Maximum flow was achieved at $3,500 \mathrm{cpm}$. Vitreous flow at $500 \mathrm{cpm}$ was not significantly different from vitreous flow at 5,000 cpm, under any vacuum condition. At $500 \mathrm{cpm}$ with $650 \mathrm{mmHg}$ of vacuum, vitreous flow was significantly higher $(P<0.05)$ than the corresponding flow in the 50/50 duty cycle mode. Flow with the biased open duty cycle setting at 5,000 cpm was $3.7 \pm 0.9 \mathrm{~mL} / \mathrm{min}$ (with $650 \mathrm{mmHg}$ ), a value that was statistically similar to the maximum flow in the biased closed and 50/50 duty cycle modes.

\section{0-gauge results}

Maximum flow rates with each duty cycle setting (at $650 \mathrm{mmHg}$ and 5,000 cpm) through 20-gauge probes were $1.9 \pm 0.3$ times higher than the corresponding maximum flow rates through 23-gauge probes (Figure 4).

In the biased closed duty cycle mode with $650 \mathrm{mmHg}$ of vacuum, vitreous flow was strongly dependent on cut rate, ranging from $1.6 \pm 0.4 \mathrm{~mL} / \mathrm{min}$ (at $500 \mathrm{cpm}$ ) to $7.7 \pm 2.1 \mathrm{~mL} / \mathrm{min}$ (at 5,000 cpm) (Figure 4A). The slopes of trend lines calculated for these data were $1 \mu \mathrm{L} /$ cut with the 450 and $650 \mathrm{mmHg}$ vacuum settings and $0.4 \mu \mathrm{L} / \mathrm{cut}$, with the $250 \mathrm{mmHg}$ vacuum setting (all $R^{2} \geq 0.88$ ).
Compared with the biased closed duty cycle mode, vitreous flow in the 50/50 duty cycle mode was not as strongly dependent on cut rate. The trend line for the $250 \mathrm{mmHg}$ series increased linearly $\left(R^{2}=0.88\right)$, with a slope of $0.3 \mu \mathrm{L} /$ cut. Flow increased nonlinearly in the 450 and $650 \mathrm{mmHg}$ series (both $R^{2}<0.7$ ), with a slope of $0.6 \mu \mathrm{L} /$ cut with $450 \mathrm{mmHg}$ vacuum and $0.5 \mu \mathrm{L} /$ cut with $650 \mathrm{mmHg}$ vacuum. In the $50 / 50$ duty cycle mode at $500 \mathrm{cpm}$, the vitreous flow was significantly higher $(P<0.05)$ than the corresponding flow in the biased closed duty cycle mode, for both the 450 and $650 \mathrm{mmHg}$ settings (Figure 4B). At 5,000 cpm, maximum flow with the $50 / 50$ duty cycle setting was $8.5 \pm 2.4 \mathrm{~mL} / \mathrm{min}$ (with $650 \mathrm{mmHg}$ vacuum), statistically similar to corresponding maximum flow rate in the biased closed duty cycle setting.

In the biased open duty cycle mode, vitreous flow was essentially constant across cut rates (Figure 4C), with all $R^{2} \leq 0.3$. Flow rates with the biased open duty cycle setting at $5,000 \mathrm{cpm}$ were $7.5 \pm 1.3 \mathrm{~mL} / \mathrm{min}$. Maximum flow rates in the biased closed duty cycle mode were achieved at 3,500 cpm $(9.5 \pm 2.0 \mathrm{~mL} / \mathrm{min})$ and were statistically similar to maximum flow rates in the 50/50 duty cycle mode. Vitreous flow at $500 \mathrm{cpm}$ was not significantly different at 5,000 cpm under any vacuum condition.

\section{Vitreous versus aqueous flow}

Figure 5 shows a comparison of flow in the biased open mode (the maximum flow) for vitreous and BSS. Results are shown with $650 \mathrm{mmHg}$ applied vacuum, except for the 20 -gauge results, which are shown at the more clinically relevant $250 \mathrm{mmHg}$ vacuum setting. In all cases, aqueous flow was at least four times higher and as much as 19 times higher than vitreous flow. In the 50/50 duty cycle mode (data not shown), the same test parameters shown in Figure 5 produced aqueous flow rates that were four to 16 times higher than vitreous flow. In the biased closed duty cycle mode (data not shown), aqueous flow rates were three to 17 times higher than vitreous flow rates. In all three duty cycle modes, the aqueous/vitreous ratios were smallest at maximum cut speeds and were largest at lower cut speeds.

\section{Discussion}

The present study demonstrated that changing the duty cycle modes on the vitrectomy system could alter vitreous flow rates through dual pneumatic vitrectomy probes; the degree of this alteration differed according to probe gauge and cut rate. In the biased closed mode, vitreous flow rates tended to increase linearly; however, with the 50/50 duty cycle, vitreous flow rate increased nonlinearly with cut rate in enhanced 

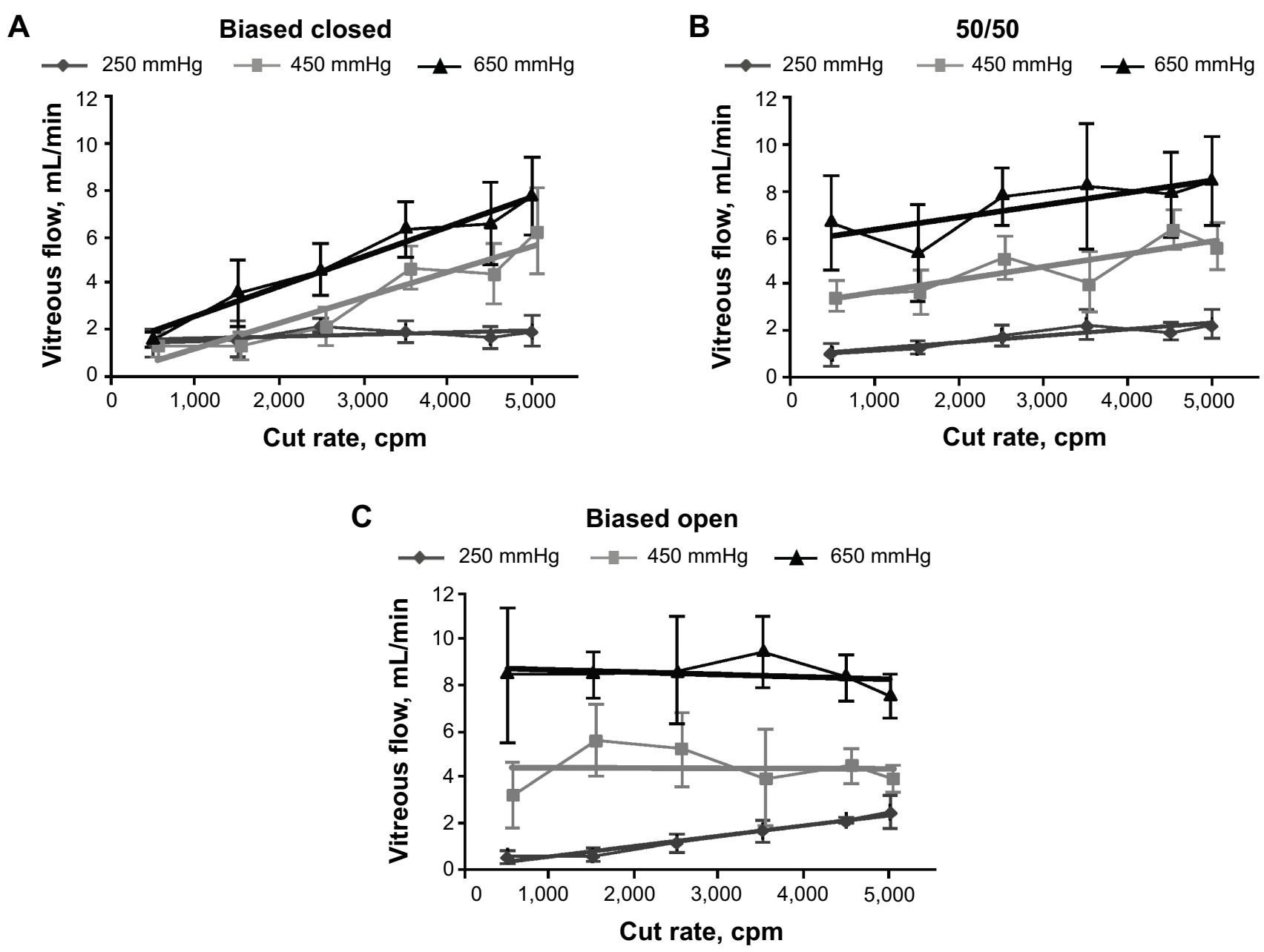

Figure 4 Vitreous flow through 20-gauge probes.

Notes: Each data point represents the average flow rate calculated from six probes, with error bars representing $95 \%$ Cls. (A) Biased closed duty cycle; (B) $50 / 50$ duty cycle; (C) biased open duty cycle. Bold lines indicate linear regression trends.

Abbreviations: $\mathrm{Cl}$, confidence interval; cpm, cuts per minute.

25 -gauge probes, whereas a linear increase was observed with 25-, 23-, and 20-gauge probes. With the biased open duty cycle, flow rate was relatively constant with increasing cut rate once a maximum flow rate had been achieved; however, the cut rate at which maximum flow occurred differed among probes (eg, 2,500 cpm with 25-gauge probes vs $5,000 \mathrm{cpm}$ with enhanced 25 -gauge probes). When compared overall under several experimental conditions, flow through enhanced 25-gauge probes was higher than flow through 25-gauge probes. Maximum flow through the 23 -gauge probes was approximately three times higher than through the 25-gauge probes, and maximum flow through the 20 -gauge probes was roughly two times higher than through the 23-gauge probes.

Aqueous flow rates were greater than that of vitreous in all duty cycle modes. However, the aqueous/vitreous ratios were smallest with high cut rate and largest at low cut rates, indicating that vitreous flow was more predictable and behaved more like aqueous fluid at higher cut rates. In biased open duty cycle mode, aqueous flow decreased with increasing cut rate, whereas vitreous flow rate remained relatively constant; in 50/50 duty cycle mode, aqueous flow rate was unaltered with increasing cut rate, but vitreous flow rate increased slightly. ${ }^{10}$ In biased closed duty cycle mode, aqueous and vitreous flow rates increased with increasing cut rate.

These differences between aqueous and vitreous flow rate may be attributable to the greater fragmentation of the vitreous with increased cut rates and the resulting reduced resistance to flow. In the biased open duty cycle, the reduction of resistance offsets the typical reduction in flow associated with increased cut rate, allowing a constant flow of vitreous material. In 50/50 duty cycle mode, as the cut rate increases, the overall cut cycle time decreases and port open time 

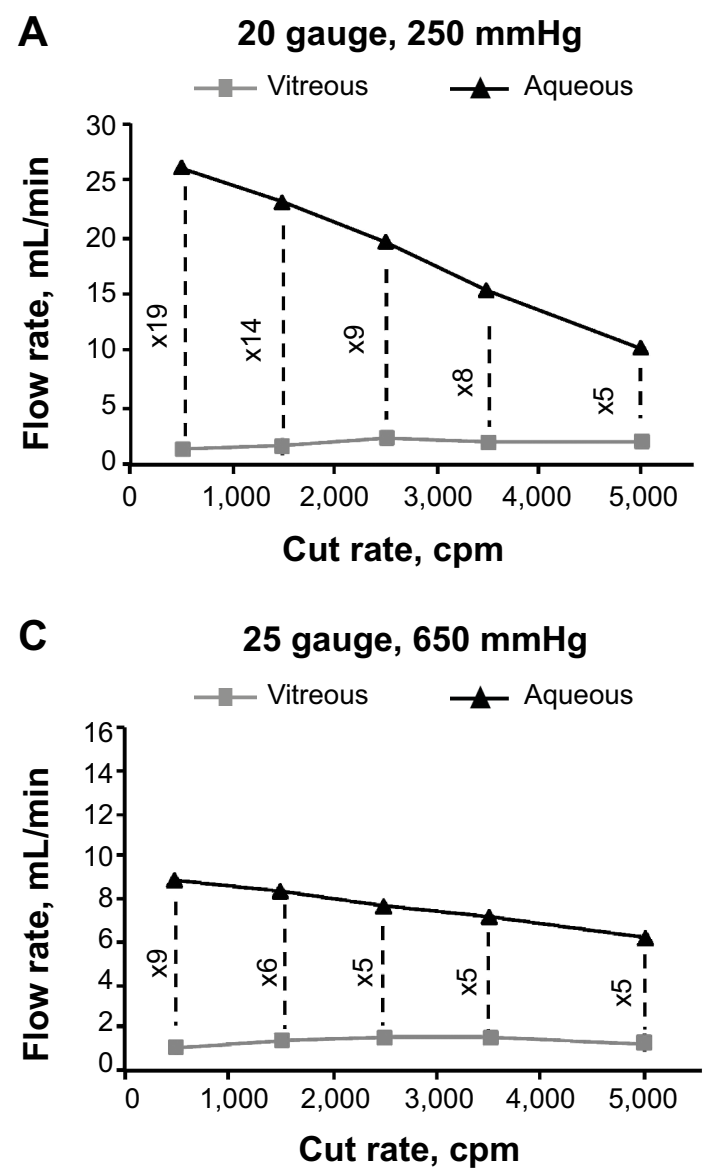
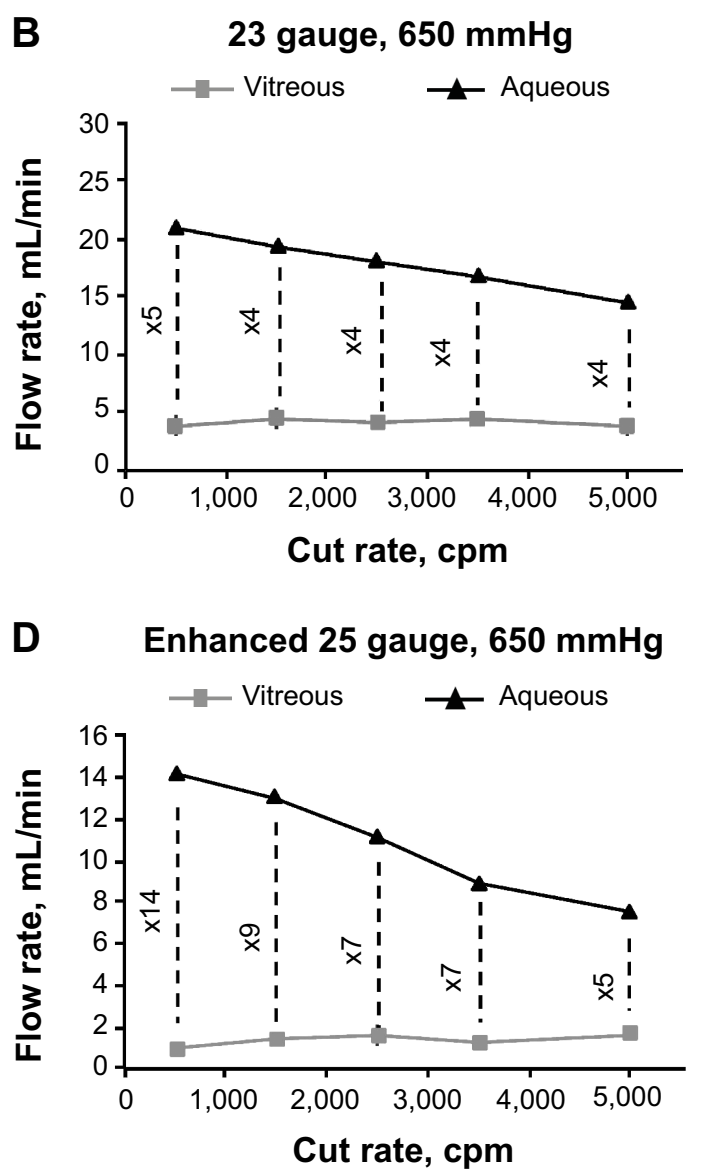

Figure 5 Comparison of flow for vitreous body and for buffered saline solution ("aqueous").

Notes: All results are for the biased open duty cycle mode and represent average flow rate calculated from six probes. Fold differences between vitreous and aqueous flow are provided. (A) 20-gauge probe; (B) 23-gauge probe; (C) 25-gauge probe; (D) enhanced 25-gauge probe.

Abbreviation: cpm, cuts per minute.

decreases proportionally to maintain the $50 \%$ duty cycle. The resulting decrease in port open time associated with high cut rate increases vitreous fragmentation and overall flow. In biased closed duty cycle mode, port open time remains constant with increasing cut rate, while total cut cycle time decreases. At higher cut rates, there is an increased frequency of cuts compared with lower cut rates and therefore greater vitreous fragmentation and flow.

Aqueous flow of BSS was four to 19 times higher than vitreous flow in this study. This result is in line with approximate ratios reported for the highest vacuum, cutter-engaged conditions in other studies: from 5 to $30,{ }^{5} 4$ to $11,{ }^{7}$ or 6 to $60 .{ }^{11}$ In this study, the ratios of aqueous/vitreous flow rates were most similar at maximum cut speeds. The viscosity-lowering effect of the high-speed cutter operating at 5,000 cpm yielded flow of vitreous body that was as little as four times lower than the flow of BSS. Thus, surgeons are able to take advantage of high cut rates, which reduce vitreous viscosity and therefore, may lessen surgical complications, such as retinal tears, without sacrificing overall flow rate. The aqueous/vitreous flow ratio results indicate that a surgeon could manipulate a probe operating at 5,000 cpm through the heterogeneous and dynamic environment of the eye without encountering large abrupt changes in flow rate as vitreous is replaced by less viscous saline solutions at the later stages of surgery.

The limitations of this study include the use of some parameters that did not perfectly simulate in vivo conditions. The vitreous flow was measured with an open-sky method, whereas the aqueous flow was tested in a closedglobe setup with a rigid, nondeformable model eye. The refrigerated animal vitreous had a viscosity that would not precisely match the viscosity of the vitreous body in a living human eye. Still, the results can provide valuable information to surgeons regarding evaluation of instrument choices and settings.

In conclusion, the increased utility and flexibility of dual pneumatic probes allowed for manipulation of porcine 
vitreous flow rates by altering the duty cycle modes on the CONSTELLATION Vision System. Operation of the probes at 5,000 cpm yielded more optimal vitreous flow rates.

\section{Acknowledgments}

This study was supported by funding from Alcon Research, Ltd. Medical writing assistance was provided by Jillian Gee, $\mathrm{PhD}$, of Complete Healthcare Communications, Inc. (Chadds Ford, PA, USA) and was funded by Alcon. The author would like to dedicate this manuscript to David Buboltz, who contributed substantially to the design and implementation of the study but who passed away prior to manuscript submission.

\section{Disclosure}

DJKA is an employee of Alcon Research, Ltd.

\section{References}

1. Hubschman JP, Gupta A, Bourla DH, Culjat M, Yu F, Schwartz SD. 20-, 23-, and 25-gauge vitreous cutters: performance and characteristics evaluation. Retina. 2008;28(2):249-257.

2. Gloor BP. The vitreous. In: Moses RA, Hart WM, editors. Adler's Physiology of the Eye: Clinical Applications. St Louis, MO: CV Mosby Company; 1987:246-267.
3. Sebag J. Age-related changes in human vitreous structure. Graefes Arch Clin Exp Ophthalmol. 1987;225(2):89-93.

4. Steel DH, Charles S. Vitrectomy fluidics. Ophthalmologica. 2011;226 Suppl 1:S27-S35.

5. Magalhaes $\mathrm{O}$, Chong L, DeBoer C, et al. Vitreous dynamics: vitreous flow analysis in 20-, 23-, and 25-gauge cutters. Retina. 2008;28(2): 236-241.

6. Diniz B, Ribeiro RM, Fernandes RB, et al. Fluidics in a dual pneumatic ultra high-speed vitreous cutter system. Ophthalmologica. 2013;229(1):15-20.

7. Fang SY, DeBoer CM, Humayun MS. Performance analysis of new-generation vitreous cutters. Graefes Arch Clin Exp Ophthalmol. 2008;246(1):61-67.

8. Oshima Y, Wakabayashi T, Sato T, Ohji M, Tano Y. A 27-gauge instrument system for transconjunctival sutureless microincision vitrectomy surgery. Ophthalmology. 2010;117(1):93-102.e2.

9. Dugel PU. Choosing a gauge for vitrectomy: why go smaller? Retinal Physician [serial on the Internet]. 2010 Oct [cited 2014 Jul 18]; October: [about 5 p.]. Available from: http://www.retinalphysician.com/ articleviewer.aspx?articleID=104860. Accessed September 18, 2014.

10. Chu TG, Buboltz DC, Abulon DJK. Comparison of aqueous flow rates with two commercially available vitrectomy systems. Abstract presented at: The Association for Research in Vision and Ophthalmology Annual Meeting; May 2-6; 2010; Fort Lauderdale, FL.

11. DeBoer C, Fang S, Lima LH, et al. Port geometry and its influence on vitrectomy. Retina. 2008;28(8):1061-1067.
Clinical Ophthalmology

\section{Publish your work in this journal}

Clinical Ophthalmology is an international, peer-reviewed journal covering all subspecialties within ophthalmology. Key topics include: Optometry; Visual science; Pharmacology and drug therapy in eye diseases; Basic Sciences; Primary and Secondary eye care; Patient Safety and Quality of Care Improvements. This journal is indexed on

Submit your manuscript here: http://www.dovepress.com/clinical-ophthalmology-journal

\section{Dovepress}

PubMed Central and CAS, and is the official journal of The Society of Clinical Ophthalmology (SCO). The manuscript management system is completely online and includes a very quick and fair peer-review system, which is all easy to use. Visit http://www.dovepress.com/ testimonials.php to read real quotes from published authors. 